\title{
"Start" Button Pressed. Game Studies Resumed
}

\section{Nikolai B. Afanasov}

Institute of Philosophy Russian Academy of Sciences. Moscow, Russia.

Email: n.afanasov[at]gmail.com

\section{Abstract}

Book review: Vetushinkiy, A. (2021). Gamedrome: The Things You Need to Know about Videogames and Game Culture. Moscow: Eksmo. (In Russian).

\section{Keywords}

Game Studies; Mediatheory; History of Videogames; Culture of Videogames; Ludology; Narratology; Practical Philosophy; Social Philosophy 


\section{Кнопка «Старт» нажата. Game Studies продолжаются}

\section{Афанасов Николай Борисович}

Институт философии РАН. Москва, Россия. Email: n.afanasov[at]gmail.com

Аннотация

Рецензия на книгу: Ветушинский, А. (2021). Игродром: что нужно знать о видеоиграх и игровой культуре. Москва: Эксмо.

Ключевые слова

исследования игр; теория медиа; история видеоигр; культура видеоигр; людология; нарратология; практическая философия; социальная философия 


\begin{abstract}
«Джилл собирается в школу. Обычно её путь включает 25-минутную поездку на метро. Она садится в поезд и располагается поудобнее перед не такой уж и короткой поездкой. Она достаёт свой смартфон и занимается привычными вещами - проверяет почту, пролистывает новые статьи, посты в Facebook, видео, которые тэгнули её друзья. Впрочем, она расправляется со всем этим довольно быстро и понимает, что до её станции ещё 20 минут, а она уже начинает скучать» (Zhang, Lee, Radharikrishnah \& Balan, 2015, p. 106).
\end{abstract}

Описанное выше многим хорошо знакомо. Часто мы сами попадаем в ситуацию, в которой оказалась Джилл: все интересные посты и видео уже просмотрены, а ехать ещё долго. К тому же не всем везёт так, как повезло Джилл. У многих жителей мегаполисов и пригородов поездка на работу или к месту учёбы занимает куда больше 25-ти минут. Возникает вопрос: чем заняться? Несмотря на то, что Джилл можно дать множество советов, несложно догадаться, что она скорее всего будет делать. В последние несколько лет картина человека, играющего в какую-нибудь мобильную игру в общественном транспорте, стала привычной настолько, что уже перестаёт обращать на себя внимание.

Свою книгу «Игродром: что нужно знать о видеоиграх и игровой культуре» (Ветушинский, 2021), вышедшую в 2021-м году в издательстве «Эксмо», ведущий российский представитель направления game studies, философ Александр Ветушинский начинает так: «Играем мы или нет, сегодня мы все живём в мире, частью которого являются видеоигры» (Ветушинский, 2021, с. 5). Первые прото-видеоигры появились более 60-ти лет назад и с тех пор отвоёвывают себе место под солнцем в конкуренции с традиционными и новыми медиа. Видеоигры, как новый вид медиа, нашли путь на домашние экраны и получили доступ ко многим кошелькам, но вплоть до настоящего момента академический дискурс game studies, или изучения видеоигр, продолжает требовать дополнительной легитимации при встрече с широкой аудиторией. Часто социально-гуманитарный подход к исследованию видеоигр не находит понимания у академического сообщества. Приведённая выше ситуация Джилл, которая стала узнаваемой в последние годы, в очередной раз показывает, что игры рядом. Финансовая статистика игровой индустрии, которая «... по обороту средств <...> уже обошла кино- и музыкальную индустрии, вместе взятые» (2021, с. 5), говорит о том же. Забегая несколько вперёд, нужно сказать, что повсеместному проникновению видеоигр в повседневность мы во многом обязаны мобильной революции: большая часть доходов игровой индустрии приходится на мобильных игроков (Dobrilova, 2021). Похоже, что именно смартфоны обеспечивают нам те впечатляющие цифры, согласно которым в мире более 2-х миллиардов геймеров (Ветушинский, 2021, с. 5).

Учитывая коммерческую природу массовой культуры, финансовые результаты игровой индустрии не позволяют медиатеории и современной философии игнорировать видеоигры. Возможно, из краткого вступления могло сложиться впечатление, что важны и актуальны именно мобильные игры, но 
это не совсем так. С точки зрения исследований, game studies - это сложная и обширная область, в которой при анализе «игры» могут быть вычленены общие закономерности, которые приближают нас к пониманию функционирования этого трудно поддающегося анализу феномена. Я полагаю, что «Игродром»это важная книга для любого, интересующегося темой, и у неё есть все шансы стать очень важной работой для развития game studies на русском языке.

Перед тем как непосредственно перейти к анализу самой книги, необходимо сказать несколько слов об её авторе, поскольку в случае с game studies в России фигура Александр Ветушинского без всякого преувеличения является одной из центральных. На первых страницах предисловия «Игродрома» Ветушинский кратко описывает свой творческий путь в исследованиях видеоигр, который начался почти 10 лет назад. Автор упоминает, что был в числе организаторов первых публичных мероприятий по философии видеоигр в Москве, «... принимал участие в работе над первым русскоязычным тематическим блогом gamestudies.ru1》 (2021, с. 7), читал курсы по видеоиграм в МГУ и НИУ ВШЭ. В 2015 году Александр Ветушинский вместе со своими коллегами подготовил блок по Game Studies для журнала «Логос»². Публикация этого блока в важном русскоязычном журнале многое сделала для легитимации и популяризации дисциплины. Несколькими годами позднее, в 2019-м году, Ветушинский принял участие в тематическом номере ещё одного влиятельного русскоязычного журнала «Новое литературное обозрение» (Ветушинский, 2019). В 2020-м году Алексей Салин и Александр Ветушинский были редакторами-составителями тематического номера журнала «Социология власти», расширив представленность исследования видеоигр в российской научной периодике (Ветушинский, 2020). Учитывая преимущества книжного формата для распространения и закрепления идей -журнальные статьи в среднем получают больше цитирований на короткой дистанции, но «монографиивведения» в какую-либо новую сферу, часто имеют большую значимость «Игродром» может стать следующей вехой в развитии game studies в России ${ }^{3}$.

«Игродром» был издан издательством «Эксмо», на первом развороте книги и её корешке стоит трейдмарк «БОМБОРА», который является частью «Эксмо», и во внутрикорпоративном делении специализируется на нонфикшн

1 В последние годы портал обновляется не так часто, но ряд материалов может представлять интерес и сегодня. См.: gamestudies.ru.

2 В этом номере есть важная статья Александра Ветушинского «Tо Play Game Studies Press the START Button», которая остаётся наиболее актуальным кратким введением в дисциплину исследования видеоигр и содержит множество ссылок на релевантные источники по теме, некоторые из которых не вошли в список литературы «Игродрома» (Ветушинский, 2015). Материалами для «Игродрома» послужили и другие статьи Ветушинского, некоторые из которых упомянуты в рецензии, что никак не отмечено в книге.

3 Нужно отметить, что в 2018-м году под редакцией Екатерины Галаниной вышла книга «Видеоигры: введение в исследования» (Галанина, 2018). Значительная часть основополагающих разделов была написана Александром Ветушинским: «Видеоигры: к вопросу об истоке», «Краткая история игровой индустрии», «История game studies как академической дисциплины», «На пути к философии видеоигр». В несколько изменённом виде эти части вошли в «Игродром». К сожалению, коллективная монография вышла тиражом всего лишь в 100 экземпляров. 
книгах, которые могут быть интересны широкому читателю, желающему почитать интеллектуальную литературу по одному из интересных сюжетов (от аниме до путешествий и психоанализа). В плане формального качества издания «Игродром» - это однозначно «Бомбора». С точки зрения популяризации знания место издательства выбрано как нельзя лучше, к тому же тираж книги 2000 копий, а не привычные для академических монографий 500 или 1000 экземпляров. Книга ярко оформлена, издана на белоснежной бумаге, текст набран крупным шрифтом, примеры сопровождены иллюстративными схемами, страницы имеют широкие поля. Всё это делает чтение удобным. Однако это увеличивает риски того, что с точки зрения развития академического знания к монографии Ветушинского могут отнестись не слишком серьёзно. К тому же работа с литературой в книге может не устроить многих учёных, предпочитающих полномасштабное сопровождение текстов постраничными ссылками. У «Игродрома» вполне объёмная библиография, но ссылок на источники в тексте не так много. Более того, объёмные и содержательные экскурсы в историю видеоигр ими часто вообе не сопровождаются, что затрудняет поиск дополнительной информации по тому или иному сюжету. История Atari и корпоративная борьба Nintendo с конкурентами не являются общеизвестными сюжетами, и, очевидно, что автор не был живым свидетелем многих описываемых историй.

«Игродром» находится в двойственном положении. С одной стороны, книга адресована массовому читателю и должна быть популярна, с другой стороны, автор претендует на то, чтобы сказать новое слово в российских game studies:

«Я старался, чтобы она (книга - Н.А.) получилась понятной, но не скатывалась в популизм; ориентированной на массового читателя, но с учётом стандартов академического письма; рассчитанной на поклонников видеоигр, но полезной и для тех, кто в них играет. В конце концов, центральная задача книги заключалась в том, чтобы в самых общих чертах познакомить читателя с миром академических исследований видеоигр, попутно погружая эти исследования в куда более широкий академический и культурный контекст и показывая, как ещё можно посмотреть на видеоигры и игровую индустрию» (Ветушинский, 2021, сс. 7-8).

Книга вошла в лонг-лист премии «Просветитель». 1 . На медиапортале «Горький» на неё была опубликована рецензия Ивана Белецкого «DOOM эпохи Возрождения: как история видеоигр повторила историю Европы» (Белецкий, 2021), из названия которой следует, что предложенная Ветушинским периодизация истории игр - о ней будет сказано далее - заинтересовала обозревателя. Белецкий пишет, что выход «Игродрома» - это важное событие, поскольку похоже, что это первый в России подобный труд «... о теории видеоигр на грани научной литературы и научпопа (в хорошем смысле слова)» (2021). В нашей рецензии мы оставим в стороне ту сторону книги, которую можно отнести к научпопу, и сосредоточимся на том, что нового привносит «Игро-

1CM.: http://www.premiaprosvetitel.ru/booksauthors/?book_id=483 
дром» в исследования видеоигр и имеет ли он ценность для развития дисициплины.

Структурно книга делится на четыре части, каждая из которых раскрывает самостоятельный сюжет: генеалогию видеоигр, историю игровой индустрии, обретение видеоиграми собственного языка и, наконец, обзор академических подходов к изучению видеоигр. В обзоре мы кратко обратимся к сюжетам каждой из этих частей. Помимо теоретического и исторического изложения сопровождающих историю видеоигр событий и теорий, автор книги предпринимает и собственные попытки рефлексивного понимания предмета, отдельно артикулируя свою позицию: «Особенно стоит отметить, что бо́льшая часть озвученных в книге идей являются авторскими» (Ветушинский, 2021, с. 8).

«Игродром» - это сложный продукт, содержащий в себе несколько пластов. Во-первых, это научно-популярное развлекательное чтение, которое для геймеров может стать «... не только исследованием, но и ностальгическим путеводителем <..> по геймерскому прошлому» (Белецкий, 2021). Во-вторых, это систематическое изложение истории развития как игр, так и изучающей их дисциплины. И, наконец, это авторское исследовательское высказывание, потенциал которого для развития осмысления феномена предстоит оценить на практике.

Первая часть книги предлагает взглянуть «... на происхождение видеоигр с трёх разных сторон: со стороны визуальных исследований, философии игры и медиатеории» (Ветушинский, 2021, с. 11). Этот раздел книги является одним из наиболее теоретически нагруженных и сложных, в чём отдаёт себе отчёт и автор:

«... фундаментальный взгляд превращает первую (по сути, вступительную) часть книги в одну из самых сложных для восприятия. Но готов заверить: без этой сложности подлинное значение видеоигр просто не удастся раскрыть» (2021, c. 11).

При чтении этого раздела становится видно, что книгу писал именно философ, стилю которого близок логический подход. Автор задаётся вопросами, ответы на которые помимо самоценности имеют ещё и структурный смысл: опыты объяснений Ветушинского в «Игродроме» могут быть не только использованы в качестве готовых заделов для исследования, но и выступить прекрасным образцом для самостоятельного анализа генеалогии игр. К примеру, разбор автором книги структуры классической игры Pong от компании Atari является прекрасным образцом того, что game studies необходимы для понимания специфики видеоигр. Логический анализ развития игр от настольного формата до экранов автоматов, телевизоров, консолей и персональных компьютеров показывает, что взгляд на историю видеоигр - это не только увлекательное и полезное мероприятие для интересующихся, но и способ понять, почему реальность именно такова. 
В качестве примера того, почему важно понимать генезис видеоигр автор приводит традиционное различие визуального отображения игр про хоккей и футбол: в футбольных симуляторах игрок смотрит на горизонтально расположенное поле, а в хоккейных - уже на вертикально-ориентированное. Исторически хоккей также был изначально «горизонтальным». Остановимся на этом частном сюжете, - в книге можно найти и другие интересные примеры - чтобы проиллюстрировать важность исторического генезиса в game studies. Beтушинский убедительно показывает, почему всё было именно так: Pong, который был «горизонтальным», трансформировался во множество игр. В своём «Наброске формальной истории видеоигр» автор приводит наглядные иллюстрированные схемы того, как из Pong получались волейбол, баскетбол, гоночные и военные игры (2021, с. 50-55). То есть первые хоккейные симуляторы просто копировали привычный дизайн. Наконец, влияние на видеоигры не исчерпывается первыми опытами написания кода. В деле и настольные игры:

«Кикер и настольный хоккей (как и аэрохоккей) в визуальном плане практически полностью идентичны тому опыту, который воспроизводится в современных футбольных и хоккейных видеоиграх. <..> В кикере поле предстаёт перед ним (игроком - Н.А.) в "горизонтальном" виде <..>, а в настольном хоккее - в "вертикальном"» (2021, с. 26).

Помимо анализа первая часть книги предлагает экскурс в философское осмысление игры в целом. «Игродрому» удаётся кратко, но содержательно познакомить читателя с тем, что говорили об играх Хёйзинга, Кайуа, Финк, Саттон-Смит. Резюме предложенного экскурса выглядит так: «Идеи описанных авторов - это надёжная основа для дальнейших размышлений о видеоиграх и их генеалогии» (2021, с. 46). Когда понятие «игры» редко входит в круг отдельно осмысляемых в социально-гуманитарных науках, исследователи часто стараются поскорее перейти к «другим вопросам». Американский учёный и геймдизайнер Ян Богост, исследования которого о видеоиграх оказывают большое влияние на дисциплину, писал: «Множество исследований видеоигр посвящены одному-единственному вопросу: что такое игра? Ещё недавно такую постановку воспринимали как бич - плеть формализма, которой нас отвлекают от более важных проблем значения, восприятия и применения видеоигр» (Богост, 2015, с. 79). «Методологическое» введение «Игродрома» оказывается к месту и не утомляет. Оно даёт понять, что можно сказать о видеоиграх в контексте общего понимания игры, но, как иронично замечает автор, история осмысления феномена игры «ничего не говорит о видеоиграх» (Ветушинский, 2021, с. 46). Ветушинский предлагает интересный ход - раз мы понимаем видеоигры в общем контексте «игры», то их нужно использовать и «... для понимания самой этой истории» $(2021$, с. 46), в которой они являются последним этапом: 
«... видеоигры - это принципиально новый и наиболее современный этап в истории игры в целом, пришедший на смену настольным играм, которые, в свою очередь, наследовали самым древним, телесным играм» $(2021$, с. 70$)$.

Вторая часть книги посвящена преимущественно историческим сюжетам из игровой индустрии. Концептуально она состоит из последовательного изложения важнейших событий, которые образуют собой «единство» истории видеоигр. Можно было бы предположить, что для академического исследователя эта часть будет представлять наименьший интерес, в то время как фанатам, которые ещё помнят интерфейсы первых консолей, она доставит удовольствие. Я полагаю, что это не так. Вторая часть книги самая объёмная, Ветушинскому удалось систематизировать и кратко представить запутанную корпоративную историю игровой индустрии. Само по себе это заслуживает внимания. Для академического исследователя эта часть важна по ряду причин. В первой части «Игродрома» было показано, насколько важным может быть знание истории и теории игры для объяснения того, как она выглядит и функционирует. Соответственно, при наличии исследовательского интереса к какой-либо игре, игровому устройству, политике игровой компании, культуре, возникшей вокруг чего-то связанного с игровым миром, будет не лишним знать об Atari, Sega, Nintendo, Sony, Microsoft. Нельзя сказать, что ответ обязательно будет в истории, но, если он там всё таки был, «изобретать» будет ненужно. В этой части книги автор «... решил использовать самую привычную периодизацию, призванную ухватить особенности европейской истории» (2021, с. 73), в уместности которой, как он предполагает, читатель сможет убедиться (2021, с. 74). Мы вернёмся к этому сюжету в заключительной части рецензии, а пока заметим, что структура второй части «Игродрома» Ветушинского вызовет приятную ностальгию у многих, кто привык работать с отечественными историческими исследованиями какого-либо феномена. Часто они выстраиваются по формуле «раскрытие феномена X в его собственной динамике и специфике»+ «феномен X в России». Так и «Игродром» предлагает вспомнить путь игровой отрасли в нашей стране.

В третьей части книги автор предлагает концептуальные размышления, призванные укрепить нас в вере, что видеоигры обладают собственной нередуцируемой к другим медиа спецификой и, соответственно, требуют собственной теоретической оптики. Для game studies и их легитимации в исследовательском поле - это важнейшая часть. Ветушинский, мышление которого тяготеет к построению логичных и формальных схем, предлагает и свою концептуальную доминанту развития видеоигр: «конец воображения»:

«... в конце 1990-х годов в истории видеоигр произошёл принципиальный сдвиг, который можно назвать "концом воображения" и который позволяет описать принципиальное различие в восприятии видеоигр, каким оно было до и каким стало после конца 1990-х» (2021, с. 166). 
Что «конец воображения» может сказать об эволюции видеоигр? Автор подчёркивает, что речь не идёт о психологическом: «... "конец воображения" это имя технологического сдвига, приведшего к тому, что воображение перестало играть ключевую роль в поддержании игрового опыта» (Ветушинский, 2021, с. 176). Ветушинский развивает свою мысль, показывая, что в истории видеоигр прослеживается не только случайная логика, восходящая к успехам и неудачам корпоративного менеджмента игровой индустрии, но и содержательный аспект, который можно развернуть в будущее. Эвристический потенциал этой идеи позволяет сделать выводы и о будущем видеоигр: «... следующим шагом должна стать полноценная VR-революция, способная сделать ещё менее ощутимой дистанцию, отделяющую игрока от игры» (2021, с. 184). Идея очень интересная, и её продуктивность предстоит оценить при работе с видеоиграми. Также оптика «конца воображения» позволяет встроить нарратив истории видеоигр в более общую теорию медиа, а, возможно, и дополнить последний. Если история видеоигр дополняет историю игр вообще, то и история видеоигр как медиа должна делать тоже самое. Как известно, классик медиатеории Маршалл Маклюэн указывал на то, что медиа «приближаются» (Маклюэн, 2007) к человеку: от дистанции в несколько десятков метров в античных и средневековых театрах, всё ближе к глазам: через экраны кинозалов, телевизоров в гостиных и, наконец, смартфонов. VR-гарнитуры продолжают этот ряд, освобождая от необходимости «брать в скобки» посредством воображения и фокусировки внимания то, что находится за рамками экрана. Завершает третью часть книги глава, посвящённая хоррор-играм. На материале развития жанра автор показывает, что для того, чтобы игры продолжали пугать, им пришлось обрести свой собственный язык. Игровая индустрия оказалась рефлексивна к своим хужожественным особенностям и смогла осмыслить свою жанровую специфику: «... видеоигры достигли той стадии зрелости, когда они уже перестали смотреть по сторонам, но сами обрели собственный голос» (Ветушинский, 2021, с. 200).

Четвёртая часть книги даёт обзор академических исследований видеоигр. Очерк развития game studies будет полезен каждому, кто захочет получить ориентиры для собственных исследований. Заключительный раздел «Игродрома» познакомит читателя со спором людологов и нарратологов, процедурной риторикой, людогерменевтикой, а также вспомнит про Маркса и феминизм. Два десятилетия истории game studies не позволяют говорить о выработке общепринятых инструментальных паттеронов исследования. Профессиональных исследователей игр не так уж и много, а методология и подходы фрагментированы. Многие исследования проводятся теми, кто уже состоялся в другой гуманитарной области, имеет свои интересы, но чувствует необходимость сказать что-то и о новом феномене. Нарратология - подход, который многим обязан исследованиям литературы, фокусируется на том, о чём рассказывают игры, адаптируя язык повествования игры к более 
привычному социально-гуманитарному (кон-)тексту, содержание которого может быть исследовано привычным и проверенным инструментарием. Людология, хронологически имевшая первенство в развитии game studies (2021, с. 213), акцентирет своё внимание на то, какил специфическим образом функционируют видеоигры.

Выстраивая возможные мостики к смежным дисциплинам социальногуманитарного профиля, автор пишет о том, что в рамках нарратологического подхода многие исследователи обратились к критической оптике, востребованной в современных исследованиях культуры. Способность игр становиться авторским высказыванием, которое даёт особый эстетический и эмоциональный опыт, несомненно привлечёт исследователей, желающих сопоставить содержание этого послания с общей культурной ситуацией. Мир игр огромен и масштабен, он порождает как новые феномены, так и трансформирует уже известные сюжеты, что требует своего исследования: к примеру, внутриигровая фотография и машинима (2021, с. 253) могут быть рассмотрены сквозь оптику конвергентной культуры Генри Дженкинса (Дженкинс, 2019) и даже её обновить.

В нашем обзоре мы не стремились полностью изложить обширное содержание «Игродрома», но выбрали те сюжеты и тот ракурс их представления, которые могут оказаться полезны исследователям, которые обращают своё внимание на феномен современных игр. По части информативности книга может служить образцом того, как нужно писать обзорные труды по состоянию какой-либо отрасли знания. Содержание полностью соответствует подзаголовку книги («Что нужно знать о видеоиграх и игровой культуре»). Более того, автор предлагает читателю и нечто большее в довесок к изложению истории индустрии, теории и обзору академических подходов. Книга авторская во многих отношениях, и видно, что собственный интерес Ветушинского имеет в первую очередь философский бэкграунд, что, как пишет автор, типично для России: «... в России интерес к видеоиграм возник внутри философии» (Ветушинский, 2021, с. 260).

Именно «авторский» характер некоторых положений можно назвать дискуссионным. К примеру, смысл концептуального деления истории игровой индустрии на Древность, Античность, Средние века, Возрождение, Новое и Новейшее время может быть понято двояко. Возможно, автор придерживается этой классификации, чтобы облегчить систематизацию материала для популярного чтения, но тогда академический смысл книги от этого проигрывает. С точки зрения метафорики периоды европейской истории слишком нагружены событиями и, по-видимому, уникальны. Эта метафора оказывается слишком требовательной и жёсткой для не столь длинного периода истории видеоигр. Об этом пишет в своей рецензии и Белецкий: «Модель довольно наглядная, но порой кажется, что автор забывает о её двойной метафоричности и начинает из собственной же (условной) разбивки на периоды делать глобальные, метафизические выводы о природе игр и связанных с ними 
процессов» (Белецкий, 2021). Если же модель предлагается в качестве рабочей понятийной сетки, то хотелось бы видеть более подробное изложение параллелизма по отношению к наиболее важным феноменам в реальной истории Европы и истории игровой индустрии. Я полагаю, что авторские концептуальные высказывания Ветушинского, сделанные в «Игродроме» могут и должны стать предметом отдельной дискуссии по мере развития game studies.

К каким выводам можно прийти после прочтения «Игродрома»? Если принять во внимание, что видеоигры всё чаще попадают в фокус исследовательского внимания, то книга служит хорошим подспорьем, чтобы сориентироваться в новой отрасли. Ряд концептуальных ходов автора - таких как «конец воображения» - побуждает к самостоятельной мысли и принадлежит к оригинальным, ценным идеям. Александр Ветушинский проделал огромную работу, и закономерным её итогом стала книга, суммирующая его исследования в области game studies, для развития которых в России он лично сделал очень многое. В 2015-м году, когда тематический номер Логоса про game studies выглядел чуть ли не как провокация, Ветушинский завершил свою статью так: «Game Studies продолжаются. И если не бояться метафор, то исследования видеоигр - это многопользовательская игра с открытым миром и огромным пополняемым арсеналом инструментов, в которую можно играть вечно, так как невозможно пройти до конца. <...> You can always press START to continue...» (Ветушинский, 2015, с. 58). Что ж, game studies действительно продолжаются, и «Игродром» - это большое событие в этой набирающей обороты многопользовательской игре.

\section{Список литературы}

Dobrilova, T. (2019, March 22). 23+ Mobile Gaming Statistics for 2021 - Insights Into a \$76B Games Market. Retrieved from TechJury website: https://techjury.net/blog/mobile-gamingstatistics/

Zhang, N., Lee, Y., Radhakrishnan, M., \& Balan, R. K. (2015). GameOn: P2p Gaming On Public Transport. Proceedings of the 13th Annual International Conference on Mobile Systems, Applications, and Services, 105-119. Florence Italy: ACM. doi: 10.1145/2742647.2742660

Белецкий, И. (2021, июль 28). DOOM эпохи Возрождения: Как история видеоигр повторила историю Европы. Извлечено от «Горький» website: https://gorky.media/reviews/doomepohi-vozrozhdeniya-kak-istoriya-videoigr-povtorila-istoriyu-evropy/

Богост, Я. (2015). Бардак в видеоиграх. Логос, 25(1), 79-99.

Ветушинский, А. (2015). To Play Game Studies Press the START Button. Логос, 25(1), 41-60.

Ветушинский, А. (2019). Игровые платформы воображают за нас: Конец воображения в видеоиграх. Новое литературное обозрение, (4), 186-199.

Ветушинский, А. (2021). Игродром. Что нужно знать о видеоиграх и игровой культуре. Москва: Эксмо. 
Ветушинский, А. С. (2020). Больше, чем просто средство: Новый подход к пониманию геймификации. Социология власти, 32(3), 14-31. doi: 10.22394/2074-0492-2020-3-14-31

Галанина, Е. (Ред.). (2018). Видеоигры: Введение в исследования. Томск: Издательский Дом Томского государственного университета.

Дженкинс, Г. (2019). Конвергентная культура. Столкновение старых и новых медиа. Москва: Рипол-Классик.

Маклюэн, Г. М. (2007). Понимание медиа: Внешние расширения человека. Москва: Кучково поле.

\section{References}

Beletsky, I. (2021, July 28). DOOM of the Renaissance: How Video Game History Repeated European History. Retrieved from. "Gorky" website: https://gorky.media/reviews/doom-epohivozrozhdeniya-kak-istoriya-videoigr-povtorila-istoriyu-evropy/(In Russian).

Bogost, J. (2015). The mess in video games. Logos, 25(1), 79-99. (In Russian).

Dobrilova, T. (2019, March 22). 23+ Mobile Gaming Statistics for 2021 - Insights Into a \$76B Games Market. Retrieved from TechJury website: https://techjury.net/blog/mobile-gamingstatistics/

Galanina, E. (Ed.). (2018). Video Games: Introduction to Research. Tomsk: Tomsk State University Publishing House. (In Russian).

Jenkins, G. (2019). Convergent Culture. The Clash of Old and New Media. Moscow: Ripol-Classic.. (In Russian).

McLuhan, H. M. (2007). Understanding Media: The Outer Extensions of Man. Moscow: Kuchkovo Pole. (In Russian).

Vetushinsky, A. (2015). To Play Game Studies Press the START Button. Лozoc, 25(1), 41-60. (In Russian).

Vetushinsky, A. S. (2020). More than a Tool: A New Approach to Understanding Gamification. The Sociology of Power, 32(3), 14-31. doi: 10.22394/2074-0492-2020-3-14-31 (In Russian).

Vetushinsky, A.(2019). Gaming platforms imagine for us: The end of imagination in video games.

New Literary Review, (4), 186-199. (In Russian).

Vetushinsky, A.(2021). Gamerdrome. What you need to know about video games and gaming culture. Moscow: Eksmo.. (In Russian).

Zhang, N., Lee, Y., Radhakrishnan, M., \& Balan, R. K. (2015). GameOn: P2p Gaming On Public Transport. Proceedings of the 13th Annual International Conference on Mobile Systems, Applications, and Services, 105-119. Florence Italy: ACM. Doi: 10.1145/2742647.2742660 